Original Research Paper

\title{
Prevalence and Antibiotic-Sensitivity of Methicillin-Resistant Staphylococcus aureus (MRSA) in Pyogenic Skin Affections of Animals and Human
}

\author{
${ }^{1}$ Maha I. Hamed, ${ }^{2}$ Sylvia O. Ahmed, ${ }^{3}$ Doaa S. Sayed and ${ }^{4}$ Hossam-Elden M. Hassan \\ ${ }^{1}$ Department of Animal Medicine (Infectious Diseases), \\ Faculty of Veterinary Medicine, Assiut University, Assiut, Egypt \\ ${ }^{2}$ Department of Animal Hygiene and Zoonosis, \\ Faculty of Veterinary Medicine, Assiut University, Assiut, Egypt \\ ${ }^{3}$ Department of Dermatology, Venereology and Andrology, \\ Faculty of Medicine, Assiut University, Assiut71526, Egypt \\ ${ }^{4}$ Veterinarian in Nutrition Management, El Wadi El Gadid University, Wadi G, Egypt
}

Article history

Received: 07-02-2019

Revised: 17-03-2019

Accepted: 03-04-2019

Corresponding Author:

Maha I. Hamed

Department of Animal

Medicine (Infectious Diseases),

Faculty of Veterinary

Medicine, Assiut University,

Assiut, Egypt

Email: maha.ibrahim@aun.edu.eg

\begin{abstract}
MRSA infections commonly present as skin and soft tissue infections in man and animals. Treatment usually includes opening of abscess and drainage with or without antibiotic therapy. MRSA is usually resistant to certain antibiotics including methicillin, oxacillin, penicillin and ampicillin. Therefore, the aim of the present study was to investigate the prevalence of MRSA in man and animals with suppurative skin affections in Assiut Governorate and to test the phenotypic and genotypic antibiotic susceptibility of the isolated MRSA strains to the commonly-used antibiotics in Egyptian medical practices. MRSA were detected in 3.0\% of tested sheep and goat, $27.3 \%$ of equines, $7.7 \%$ of cows and in $14.3 \%$ of tested humans in the same area. All animal and man MRSA strains were positive to $\operatorname{erm}(A)$, TetK and TetM genes, but erm(C) gene could only be detected in $80 \%$ of human MRSA isolates. human and animal MRSA isolates were resistant to penicillin and ampicillin antibiotics with MIC ranging from 8 to 128 $\mu \mathrm{g} / \mathrm{ml}$. Sheep and cow MRSA isolates were resistant to oxytetracycline, while equine isolates were sensitive to it. About $44.4 \%$ of human isolates were resistant to oxytetracycline. All animal-derived MRSA isolates were resistant to cefixime and more than of $55 \%$ of human isolates were also resistant to the same drug. All MRSA isolates were sensitive to clindamycin except for strains isolated from cows. Enerofloxacin and ciprofloxacin were the most effective antibiotics against all MRSA isolates. None of the 16 MRSA isolates had reduced susceptibility to vancomycin with MICs laying in the $0.5-4 \mu \mathrm{g} / \mathrm{mL}$ range. The similarity in phenotypic and genotypic antibiotic susceptibility of MRSA isolates recovered from both humans and animal cases, despite the difference in the frequently used antibiotics in veterinary and human hospitals, suggesting the possibility of zoonotic circulation of those isolates between them.
\end{abstract}

Keywords: MRSA, Egypt, Zoonosis, Antibiotic Resistance Genes, Antimicrobial Sensitivity

\section{Introduction}

Methicillin-resistant Staphylococcus aureus (MRSA) has now become a major nosocomial infection worldwide (Deurenberg and Stobberingh, 2008) and a common cause of skin and soft tissue infections (Moran et al., 2006). In Egypt, the highest proportion of MRSA among invasive Staphylococcus aureus (S. aureus) strains isolated from blood cultures has been reported (Borg et al., 2007; Falagas, et al., 2013). Unfortunately, MRSA found its 
way outside hospitals to the community leading to emerging Community-Acquired Methicillin-Resistant $S$. aureus (CA-MRSA) infections (Herold et al., 1998). Animals may act as reservoir of MRSA to human (Hadjirin et al., 2015). MRSA infections have become a growing concern in the veterinary field and the appearance of Livestock-Associated Methicillin-Resistant S. aureus (LA-MRSA) has been increasingly reported worldwide (Van Cleef et al., 2010). The risk of zoonotic transmission especially for people with occupational livestock exposure is rising (Hanselman et al., 2006; Vanderhaeghen et al., 2010; Fessler et al., 2012). Interestingly, strains originating from companion animals are often human strains in origin (Bhanderi and Jhala, 2011). On the other hand, LA-MRSA are divergent from human strains may result in MRSA being an emerging zoonotic pathogen with veterinarians, cattle farmers and pet owners put at risk of acquiring the infection (Morgan, 2008). Several reports have shown that MRSA can also spread in veterinary hospital settings from humans to animals and from animals to humans and has the ability to survive in the environment (Seguin et al., 1999; Duijkeren et al., 2004; Weese et al., 2004; 2005; 2006; Baptiste et al., 2005; O'Mahony et al., 2005; Leonard et al., 2006). Using the genotypic and phenotypic methods, scientists found that there is no difference between human and bovine MRSA, which confirming MRSA transmission between cattle and human (Lee, 2003; Juhász-Kaszanyitzky et al., 2007; Hata et al., 2010).

CA-MRSA should be considered when treating skin and soft tissue infections especially in developing countries (Sobhy et al., 2012). Antimicrobial testing from suppurative skin lesions are recommended to guide individual therapy (Abdel Fattah and Darwish, 2012). MRSA causes a variety of skin affections and septic wounds in man and animals, but information about the prevalence of MRSA infection causing these affections in Egypt is scarce. Assiut Governorate in Egypt consists of rural villages where animals are usually kept in very close contact to houses of their owners. Patients with skin affections from Assiut governorate are often referred to Assiut University teaching hospital dermatology unit. Assiut University veterinary teaching hospital usually treats animals with skin abscesses and infected wounds from all Assiut Governorate villages as well. Therefore, we collected animal and human samples from patients with skin affections admitted to these two hospitals, which covers Assiut Governorate villages. The study aimed to investigate the prevalence of MRSA infection in human and animal individuals with pyogenic skin lesions and wound at Assiut Governorate, Egypt. Phenotype and genotype screening the antibiotic susceptibility of the isolated MRSA strains to the commonly used antibiotics in human and veterinary Egyptian field was also undertaken.

\section{Materials and Methods}

\section{Ethical Approval}

All the participants were informed about the objectives of the study, methods, voluntary participation and the individual information was concealed. Consents were recorded following participant agreement and their rights were clearly explained to each one of them. Also, animal samples and data were obtained after agreement of their owners.

\section{Patients}

\section{Human}

Samples were collected from 63 patients from the Assiut University hospital dermatology clinic with suppurative skin lesions, infected wounds and abscess during the period from 2015 to 2017.

\section{Animals}

Samples were collected from a three different animal species (66 sheep, 11 equines and 26 cows) that were referred to the Veterinary teaching hospital, Faculty of Veterinary Medicine, Assiut University during the same time period. These animals suffered from pyogenic skin affections, suppurating wounds and abscesses.

\section{Demographic Data of Human Patients}

Age: from less than 2 to 40 years. Gender: 40 males and 23 females. Residence: 47 patients from overcrowded bad hygienic condition rural areas, 16 patients from urban areas. Sites of skin lesions: 26 on the hand, 13 on the leg, 11 on the abdomen and breast, 9 on the buttock and 4 on the face.

\section{Samples and Bacterial Identification}

Sterile bacteriological swabs were collected from already opened skin lesions, wounds and abscesses of the diseased animals and man after disinfection of the opening with tincture iodine, while the closed abscesses were surgically incised and pus material were swabbed under septic conditions. Swabs taken from abscesses and wounds were directly inoculated into tubes containing tryptic soy broth then incubated at $37^{\circ} \mathrm{C}$ for $24-48 \mathrm{~h}$. The incubated tubes were streaked onto blood agar base enriched with $10 \%$ citrated sheep blood and on BairedParker agar used for selective isolation of Staphylococci. The inoculated plates were aerobically incubated at $37^{\circ} \mathrm{C}$ and examined for bacterial growth after 24-48 h. The plates were examined for growth, morphologic features and hemolytic characteristics following routine guidelines (Quinn et al., 1994; Carter et al., 1995). Identification of the isolated bacteria was done according to colony morphology, microscopic examination of gram stained smear and biochemical examination (Collins et al., 1991; Cruickshank et al., 1975). 
Table 1: Sequence of primer sets for antibiotic resistance genes and the amplicon size

\begin{tabular}{|c|c|c|c|c|}
\hline Resistance phenotype & Gene & Sequences of primer sets & Amplicon Size (bp) & References \\
\hline \multirow[t]{4}{*}{ Clindamycin, erythromycin } & $\operatorname{erm}(A)$ & F- AAGCGGTAAACCCCTCTGA & 190 & Strommenger et al. (2003) \\
\hline & & R- TTCGCAAATCCCTTCTCAAC & & \\
\hline & $\operatorname{erm}(C)$ & F- AATCGTCAATTCCTGCATGT & 299 & \\
\hline & & R- TAATCGTGGAATACGGGTTTG & & \\
\hline \multirow[t]{4}{*}{ Tetracycline } & tet $K$ & F-GTAGCGACAATAGGTAATAGT & 360 & \\
\hline & & R-GTAGTGACAATAAACCTCCTA & & \\
\hline & tet $M$ & F-AGTGGAGCGATTACAGAA & 158 & \\
\hline & & R-CATATGTCCTGGCGTGTCTA & & \\
\hline
\end{tabular}

\section{Detection of mecA Gene}

All isolates identified as $S$. aureus were tested for the presence of mecA gene using specific primers. DNAs from $S$. aureus isolates were extracted as described by using Dneasy Tissue Kit (QIAamp ${ }^{\circledR}$ DNA Mini Kit) with some modifications. The extracted DNA was used as a template for PCR amplification. PCR amplifications were performed with a pair of primers specific for mecA gene, synthesized from the previously published Sequences: Primer 1: 5'-AAA ATC GAT GGT AAA GGT TGG C-3', primer 2: 5'-AGT TCT GCA GTA CCG GAT TTG C-3' (Louie et al., 2009). The PCR cycles consisted of initial denaturation at $96^{\circ} \mathrm{C}$ for $5 \mathrm{~min}$, followed by 40 cycles of denaturation at $95^{\circ} \mathrm{C}$ for $30 \mathrm{~s}$, annealing at $60^{\circ} \mathrm{C}$ for $30 \mathrm{~s}$ and extension at $72^{\circ} \mathrm{C}$ for 1 min and final extension at $72^{\circ} \mathrm{C}$ for $10 \mathrm{~min}$. The PCR products were analyzed by electrophoresis in a $1.5 \%$ agarose gel containing $0.5 \mathrm{mg}$ of ethidium bromide per $\mathrm{mL}$. The size of the amplificons were estimated by comparison with a $1 \mathrm{kp}$ DNA step ladder. MRSA strain ATCC BAA-44 (KwikStik, 01055 P) was used as positive control and nuclease-free water (Promega, P119A) was used as negative control.

\section{Detection of Antibiotic Resistance Genes}

$m e c A$ gene positive MRSA isolates were examined by using PCR for the presence of some antibiotic resistance genes $(\operatorname{erm}(A), \operatorname{erm}(C), \operatorname{tet} K$, tet $M$ genes) by using specific primers (Table 1). DNAs from MRSA isolates were extracted as described by using Dneasy Tissue Kit (QIAamp® DNA Mini Kit) with some modifications. The PCR cycles consisted of initial denaturation at $96^{\circ} \mathrm{C}$ for 5 min, followed by 30 cycles of denaturation at $95^{\circ} \mathrm{C}$ for 30 $\mathrm{s}$, annealing at $55^{\circ} \mathrm{C}$ for $30 \mathrm{~s}$ and extension at $72^{\circ} \mathrm{C}$ for 1 min and final extension at $72^{\circ} \mathrm{C}$ for $10 \mathrm{~min}$. The PCR products were analyzed by electrophoresis in a $1.5 \%$ agarose gel containing $0.5 \mathrm{mg}$ of ethidium bromide per $\mathrm{ml}$. The sizes of the amplification products were estimated by comparison with a 100bp DNA step ladder.

\section{Antimicrobials Test}

mecA gene positive MRSA isolates were tested for their sensitivity towards the most commonly used antibiotics in the human and veterinary field in Egypt. These antibiotics included penicillin, ampicillin, oxytetracycline, enerofloxacin, vancomycin, ciprofloxacin, clindamycin and cefixime. Minimum Inhibitory Concentrations (MIC) of antibiotics were evaluated with the broth microdilution technique in Mueller Hinton broth (MHB) with an initial inoculum of $5 \times 10^{5}$ in non-treated Polystyrene microtiter plates in accordance with the Clinical and Laboratory Standards Institute (CLSI, 2010). The MIC were interpreted as the lowest concentration of antibiotic that completely inhibited the visible growth of bacteria after $16 \mathrm{~h}$. incubation of the plates at $37^{\circ} \mathrm{C}$. Each agent was tested in triplicate in at least two independent experiments. The highest MIC value were reported.

\section{Statistical Analysis}

The svy commands in Stata statistical software (release 15.1; 2017, Stata Corp LP, College Station, TX) was used to measure the impact of each factor individually on the occurrence of the disease. Odds ratio and $95 \%$ confidence intervals was calculated and a probability value (P-Value) $p<0.05$ was considered statistically significant.

\section{Results}

\section{Occurrence of S. aureus in Animals and Human}

S. aureus was isolated from 28 out of 103 (27.2\%) different animal species with both open and closed skin abscess. The 28 cases with $S$. aureus included 10 out of $66(15.2 \%)$ examined sheep, 7 out of $11(63.6 \%)$ examined equine and 11 out of $26(42.3 \%)$ examined cows (Table 2). Meanwhile, 63 human individuals with infected wounds after surgery or skin abscesses in different body areas (hands, legs, face, breast and buttock) were examined for $S$. aureus infection and it could be isolated by $23.8 \%$ ( 15 out of 63 ).

\section{Detection of mecA Gene}

Methicillin-Resistant $S$. aureus mecA gene positive isolates (MRSA) could be detected in $3.0 \%$ of examined sheep and goat, $27.3 \%$ of examined equines and $7.7 \%$ of examined cows (Table 2). PCR product of MRSA isolates gave positive band at $533 \mathrm{bp}$ on the agarose gel electrophoresis (Fig. 1). MRSA isolates 
could also be detected in examined human individuals with prevalence $14.3 \%$. The impact of some factors like gender, age and area on MRSA prevalence in humans has been evaluated (Table 3 ).

\section{Detection of Antibiotic Resistance Genes in MRSA Isolates}

All MRSA strains isolated from animal and human individuals were positive to $\operatorname{erm}(A), T e t K$ and TetM genes (Table 4) and PCR product showed positive bands at $190 \mathrm{bp}, 360 \mathrm{bp}$ and $158 \mathrm{bp}$ respectively (Fig. 2, 4 and 5). Meanwhile, $\operatorname{erm}(C)$ gene could not be detected in all animal MRSA isolates and were detected in $80 \%$ of human MRSA isolates (Table 4). PCR product showed positive band for erm (C) gene at 299bp (Fig. 3).

\section{Antimicrobial Testing Results}

As demonstrated in Table 5, human and animal MRSA isolates were resistant to penicillin and ampicillin antibiotics with MIC ranging from 8 to $128 \mu \mathrm{g} / \mathrm{ml}$. Sheep and cow MRSA isolates were resistant to oxytetracycline, while equine isolates were sensitive to it. About $44.4 \%$ of human isolates were resistant to oxytetracycline. All animal MRSA isolates were resistant to cefixime and more than of $55 \%$ of human isolates were also resistant to it. All MRSA isolates were sensitive to clindamycin except for cow's strains. Enerofloxacin and ciprofloxacin were the most effective antibiotics against all MRSA isolates. None of the 16 MRSA isolates had reduced susceptibility to vancomycin with MICs laying in the $0.5-4 \mu \mathrm{g} / \mathrm{ml}$ range.

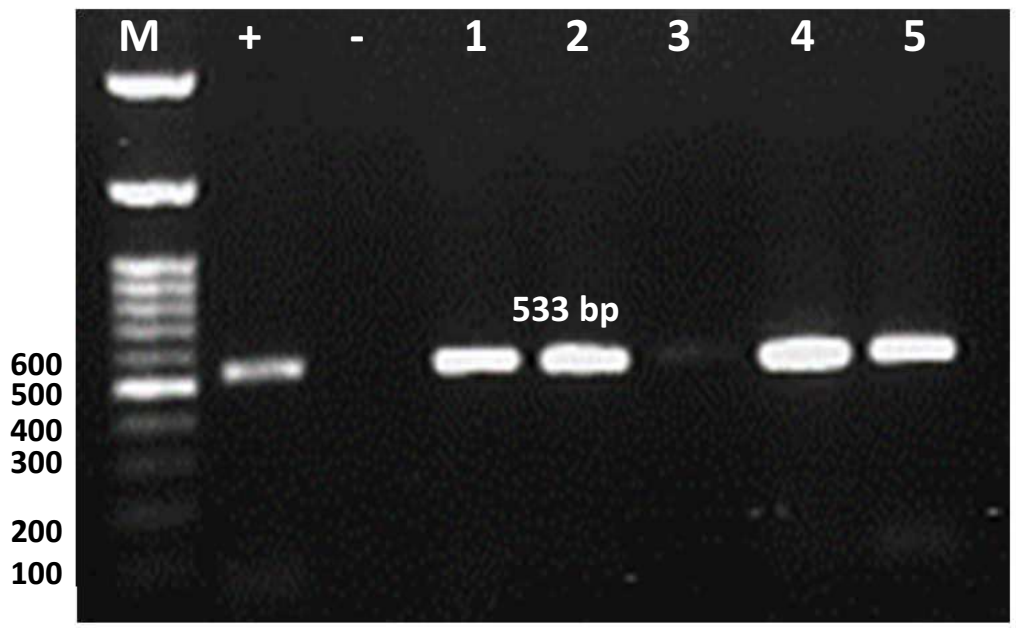

Fig. 1: Agarose gel electrophoresis showing PCR products of mecA gene positive $S$. aureus isolates from animal and human cases with skin affections (positive band at $533 \mathrm{bp}$ ). $\mathrm{M}=100 \mathrm{bp}$ ladder, lane $(+)=$ positive control, lane $(-)=$ negative control, lane $(1,2,4,5)=$ positive samples and lane $(3)=$ negative sample

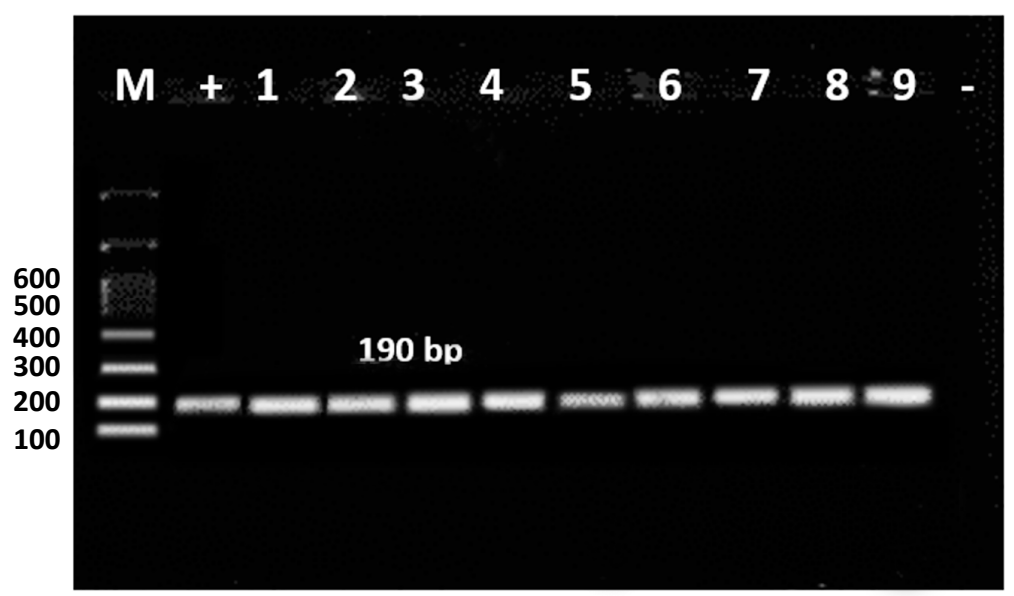

Fig. 2: Agarose gel electrophoresis showing PCR products of erm(A) gene positive $S$. aureus isolates from animal and human cases with skin affections (positive band at $190 \mathrm{bp}$ ). lane $(+)=$ positive control, lane $(-)=$ negative control, lane $(1,2,3,4,5,6,7,8,9)=$ positive samples 


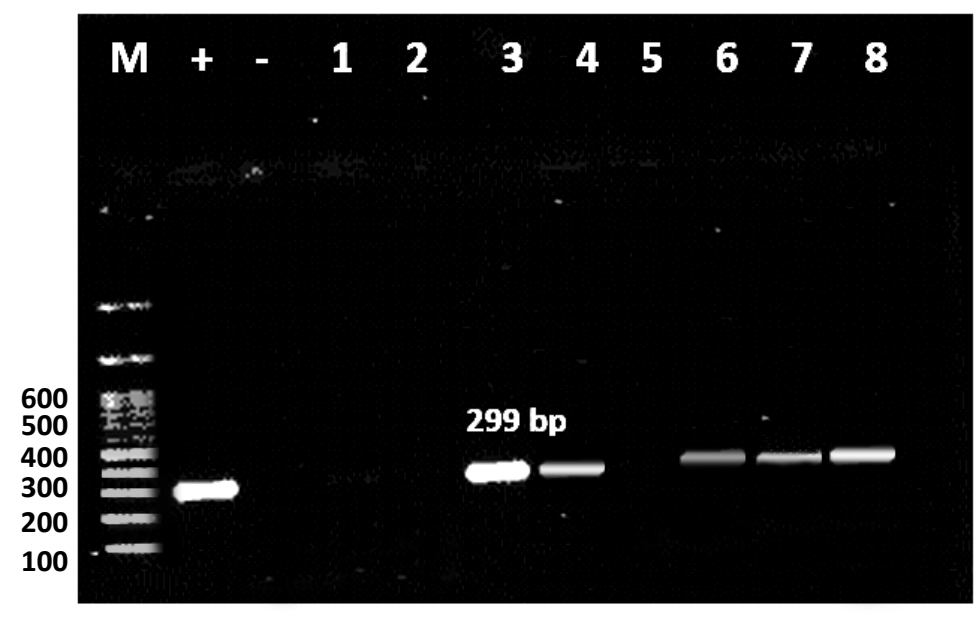

Fig. 3: Agarose gel electrophoresis showing PCR products of erm $(C)$ gene positive $S$. aureus isolates from animal and human cases with skin affections (positive band at $299 \mathrm{bp}$ ). lane $(+)=$ positive control, lane $(-)=$ negative control, lane $(3,4,6,7,8)=$ positive samples and lane $(1,2,5)=$ negative samples

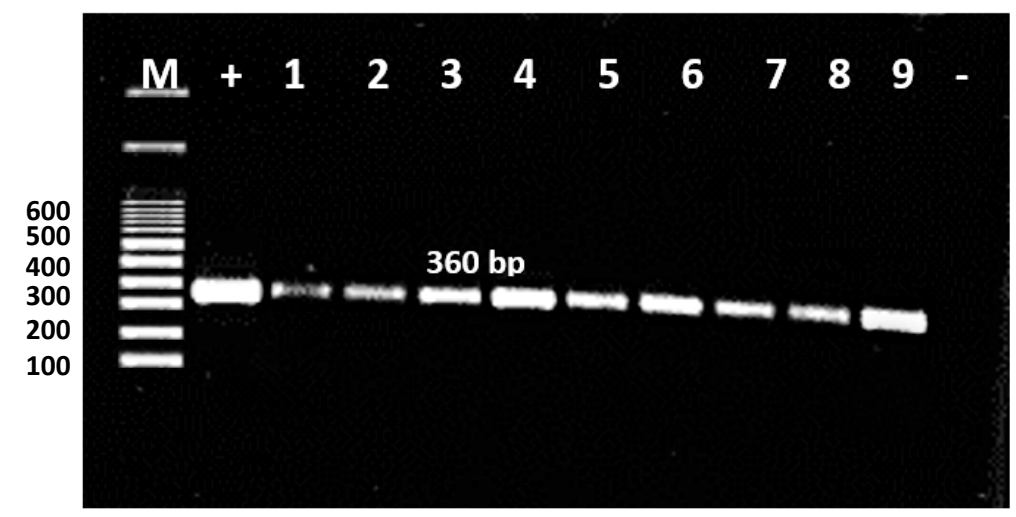

Fig. 4: Agarose gel electrophoresis showing PCR products of tet $K$ gene positive $S$. aureus isolates from animal and human cases with skin affections (positive band at $360 \mathrm{bp}$ ). lane $(+)=$ positive control, lane $(-)=$ negative control, lane $(1-9)=$ positive samples

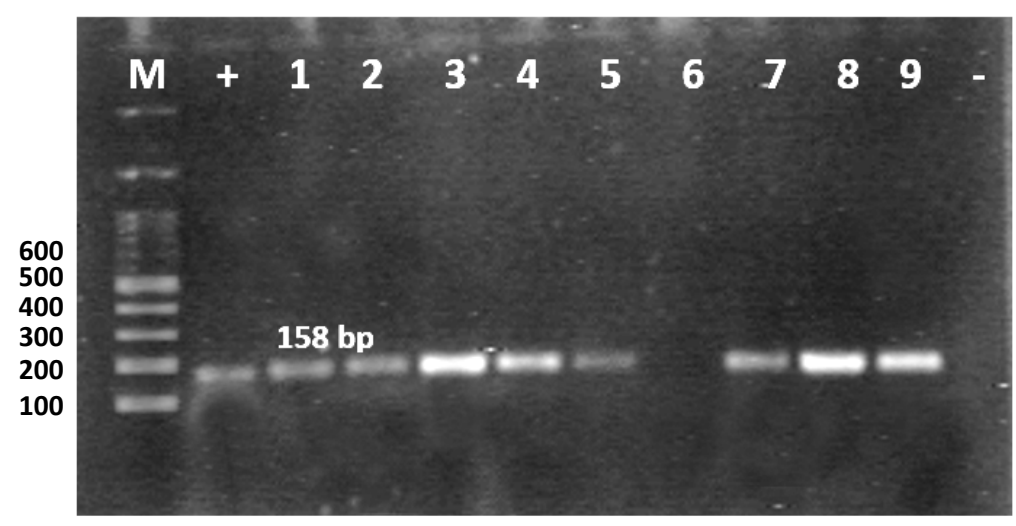

Fig. 5: Agarose gel electrophoresis showing PCR products of tet $M$ gene positive $S$. aureus isolates from animal and human cases with skin affections (positive band at $158 \mathrm{bp}$ ). lane $(+)=$ positive control, lane $(-)=$ negative control, lane $(1,2,3,4,5,7,8,9)=$ positive samples and lane $(6)=$ negative sample 
Maha I. Hamed et al. / American Journal of Animal and Veterinary Sciences 2019, 14 (1): 57.68 DOI: $10.3844 /$ ajavsp.2019.57.68

Table 2: Prevalence of MRSA among animals with skin affections

\begin{tabular}{|c|c|c|c|c|c|c|}
\hline \multirow[b]{2}{*}{ Species } & \multirow[b]{2}{*}{ No. tested } & \multicolumn{2}{|c|}{ Positive $S$. aureus (\%) } & \multirow[b]{2}{*}{ Odds ratio } & \multirow[b]{2}{*}{$95 \%$ CI } & \multirow[b]{2}{*}{ P Value } \\
\hline & & MRSA (\%) & MSSA (\%) & & & \\
\hline Sheep and goat & 66 & $2(3.0)$ & $8(12.1)$ & 6.39 & $2.05-19.92$ & 0.001 \\
\hline Equine & 11 & $3(27.3)$ & $4(36.4)$ & & & \\
\hline Cow & 26 & $2(7.7)$ & $9(34.6)$ & & & \\
\hline Total & 103 & $7(6.8)$ & $21(20.4)$ & & & \\
\hline
\end{tabular}

$95 \%$ confidence intervals $(95 \% \mathrm{CI})$, probability value (P-Value)

Table 3: Prevalence of MRSA among human individuals with skin affections

\begin{tabular}{|c|c|c|c|c|c|c|}
\hline \multirow[b]{2}{*}{ Factor } & \multirow[b]{2}{*}{ No. tested } & \multicolumn{2}{|c|}{ Positive $S$. aureus (\%) } & \multirow[b]{2}{*}{ Odds ratio } & \multirow[b]{2}{*}{$95 \% \mathrm{CI}$} & \multirow[b]{2}{*}{ P Value } \\
\hline & & MRSA (\%) & $\operatorname{MSSA}(\%)$ & & & \\
\hline \multicolumn{7}{|l|}{ Gender } \\
\hline Male & 40 & $7(17.5)$ & $3(7.5)$ & 0.45 & $0.09-2.37$ & 0.35 \\
\hline Female & 23 & $2(8.7)$ & $3(13.0)$ & & & \\
\hline Total & 63 & $9(14.3)$ & $6(9.5)$ & & & \\
\hline \multicolumn{7}{|c|}{ Age (Year) } \\
\hline$>2-20$ & 29 & $3(10.3)$ & $2(6.9)$ & 1.43 & $0.57-3.59$ & 0.45 \\
\hline $20-40$ & 23 & $4(17.4)$ & $4(17.4)$ & & & \\
\hline $40-70$ & 11 & $2(18.2)$ & 0 & & & \\
\hline Total & 63 & $9(14.3)$ & $6(9.5)$ & & & \\
\hline \multicolumn{7}{|l|}{ Area } \\
\hline Rural & 47 & $8(17.0)$ & $4(8.5)$ & 0.66 & $0.49-0.87$ & 0.003 \\
\hline Urban & 16 & $1(6.3)$ & $2(12.5)$ & & & \\
\hline Total & 63 & 9 & 6 & & & \\
\hline
\end{tabular}

95\% confidence intervals $(95 \% \mathrm{CI})$, probability value (P-Value)

Table 4: Correlation between phenotypic antibiotic resistance and PCR results of antibiotic resistance genes in MRSA isolates.

\begin{tabular}{|c|c|c|c|c|c|c|}
\hline Isolates & Resistance phenotype & mecA & $\operatorname{erm}(A)$ & $\operatorname{erm}(C)$ & tet $K$ & tetM \\
\hline \multicolumn{7}{|l|}{ Animal isolates } \\
\hline \multirow[t]{2}{*}{ Sheep and goat } & PEN, OTE, CEF, AMP & + & + & - & + & + \\
\hline & PEN, OTE, CEF, AMP & + & + & - & + & + \\
\hline \multirow[t]{3}{*}{ Equine } & PEN, CEF, AMP & + & + & - & + & + \\
\hline & PEN, CEF, AMP & + & + & - & + & + \\
\hline & PEN, CEF, AMP & + & + & - & + & + \\
\hline \multirow[t]{2}{*}{ Cows } & PEN, OTE, CLI, CEF, AMP & + & + & - & + & + \\
\hline & PEN, OTE, CLI, CEF, AMP & + & + & - & + & + \\
\hline \multicolumn{7}{|l|}{ Human isolates } \\
\hline \multirow[t]{2}{*}{ Female } & PEN, OTE, AMP & + & + & + & + & + \\
\hline & PEN, CEF, AMP & + & + & - & + & + \\
\hline \multirow[t]{7}{*}{ Male } & PEN, AMP & + & + & - & + & + \\
\hline & PEN, OTE, AMP & + & + & + & + & + \\
\hline & PEN, OTE, AMP & + & + & + & + & + \\
\hline & PEN, CEF, AMP & + & + & + & + & + \\
\hline & PEN, CEF, AMP & + & + & + & + & + \\
\hline & PEN, OTE, CEF, AMP & + & + & + & + & + \\
\hline & PEN, CEF, AMP & + & + & + & + & + \\
\hline
\end{tabular}

PEN, penicillin; CLI, clindamycin; OTE, oxytetracycline; CEF, cefixime; AMP, ampicillin.

Table 5: Minimum inhibitory concentrations of the common used antibiotics in field $(\mu \mathrm{g} / \mathrm{ml})$ against animal and human MRSA isolates

\begin{tabular}{|c|c|c|c|c|c|c|c|c|c|c|c|c|c|c|c|c|}
\hline \multirow{4}{*}{$\begin{array}{l}\text { Antibiotics } \\
\text { Penicillin }\end{array}$} & \multicolumn{16}{|c|}{$\mathrm{MIC}(\mu \mathrm{g} / \mathrm{ml})$} \\
\hline & \multicolumn{7}{|c|}{ Animal Isolates } & \multicolumn{9}{|c|}{ Human Isolates } \\
\hline & \multicolumn{2}{|c|}{ Sheep isolates } & \multicolumn{3}{|c|}{ Equine isolates } & \multicolumn{2}{|c|}{ Cow isolates } & \multicolumn{2}{|c|}{ Female isolates } & \multicolumn{7}{|c|}{ Male isolates } \\
\hline & 8 & 64 & 16 & 8 & 32 & 32 & 32 & 32 & 16 & 32 & 32 & 64 & 8 & 32 & 8 & 32 \\
\hline Oxytetracycline & 64 & 64 & 0.25 & 0.125 & 0.25 & 16 & 16 & 64 & 0.125 & 0.125 & 64 & 64 & 0.125 & 0.25 & 64 & 0.125 \\
\hline Enrofloxacin & 0.125 & 0.125 & 0.5 & 0.125 & 0.125 & 0.125 & 0.125 & $<0.03125$ & $<0.03125$ & 0.125 & $<0.03125$ & 0.125 & 0.125 & 0.25 & $<0.03125$ & 0.25 \\
\hline Vancomycin & 0.5 & 1 & 2 & 1 & 1 & 4 & 4 & 1 & 1 & 1 & 1 & 1 & 1 & 1 & 0.5 & 1 \\
\hline Ciprofloxacin & 0.5 & 0.25 & 2 & 0.5 & 0.25 & 0.25 & 0.25 & 0.25 & 0.125 & 0.25 & 0.25 & 0.25 & 0.5 & 0.5 & 0.25 & 0.5 \\
\hline Clindamycin & 0.125 & 0.125 & 0.125 & 0.125 & 0.125 & 64 & 64 & 0.125 & 0.125 & 0.125 & 0.125 & 0.125 & 0.125 & 0.125 & 0.125 & 0.125 \\
\hline Cefixime & 8 & 8 & 8 & 8 & 8 & 8 & 8 & 1 & 8 & 1 & 1 & 1 & 8 & 8 & 128 & 8 \\
\hline Ampicillin & 16 & 128 & 16 & 32 & 64 & 64 & 64 & 32 & 16 & 64 & 64 & 64 & 64 & 16 & 32 & 16 \\
\hline
\end{tabular}




\section{Discussion}

MRSA is one of the most problematic pathogens in veterinary and human medicine. The increasing number of MRSA cases detected in Egypt necessitates the continuous monitoring of the epidemiological phenotypic and genotypic antimicrobial susceptibility features of MRSA infections (Abd El-Hamid and Bendary, 2015). Moreover, the recovery of MRSA from various animal species increases the concern about the role of animals in MRSA infection in human (Weese, 2010). The current investigation was carried out to detect MRSA prevalence at Assiut Governorate, Egypt and to compare the phenotypic and genotypic antibiotic resistance of the isolated MRSA strains.

MRSA was first isolated from milk of mastitic cows (Devriese and Hommez, 1975), then it could be isolated from other animal species including dogs, cats, pigs, horses and poultry worldwide (Leonard and Markey, 2008). MRSA was identified in the present study from cattle with septic skin infections by $7.7 \%$. This finding was similar to Jayaweera and Kumbukgolla (2017), who reported prevalence rate $6.2 \%$ from nasal and perineal swabs from cattle. Meanwhile, despite the high number of sheep and goat with skin abscesses subjected to this study, the estimated prevalence of MRSA was low $(3.0 \%)$. This finding came in agreement with other investigations carried out on small ruminants (Giacinti et al., 2017; Caruso et al., 2015; Cortimiglia et al., 2015) in Italy, (Ariza-Miguel et al., 2014) in Spain and (Pexara et al., 2005) in Greece, who reported prevalence rates ranged from $0-2 \%$.

The highest MRSA prevalence was recorded in equine $(27.3 \%)$, despite the low number of examined horses with septic wounds and skin abscesses. The difference in MRSA prevalence between equine and other animal species recorded in this study was of high significance $(\mathrm{OR}=6.39,95 \% \mathrm{CI}=2.05-19.92,=0.001)$. MRSA reported as emerging pathogen in veterinary medicine especially in small animals and equine (Leonard and Markey, 2008). Wound infections and post-operative contaminations are the most common manifestation of MRSA in horses. The principle route of transmission is contaminated hands of veterinary personnel (Weese et al., 2004). The emergence of MRSA as an equine pathogen implies that horses could be a community reservoir of MRSA and a source of infection to human (Weese et al., 2005).

Nine out of $63(14.3 \%)$ human patients with suppurative skin lesions were positive to MRSA infection. The prevalence of CA-MRSA in the present study agreed with Abdel-Maksoud et al. (2016), who recorded $11.5 \%$ prevalence of CA-MRSA in Egypt. Also, this finding was in concordance with findings reported in other studies done in Egypt (Guirguis, 2004). A previous study by Ahmed et al. (2014) in Egypt at
Minya Governorate, which is the geographically close to Assiut, recovered MRSA from infected skin and soft tissue sites in $31(15 \%)$ out of 208 patients admitted to Minya University hospital. The prevalence rate of CAMRSA in Egypt is probably due to the self-medication with antibiotics for mild bacterial or viral infections, where antibiotics usually received without prescription (Sabry et al., 2014). Baddour et al. (2006) studied the antibiotic susceptibility pattern of MRSA isolates from several hospitals in Saudi Arabia and concluded that the inappropriate use of antibiotics is an important cause of the increasing prevalence of resistant bacteria as MRSA in developing countries.

Prevalence of MRSA in male patients was $17.5 \%$ while it was $8.7 \%$ in females. This finding meant that 77 . $8 \%$ of recovered MRSA isolates from human patients were from males. Despite this finding was statistically insignificant $(\mathrm{OR}=0.45,95 \% \mathrm{CI}=0.09-2.37, \mathrm{P}=0.35)$, it was similar to those recorded by Baddour et al. (2006), Tentolouris et al. (2006) and Van Belkum et al. (1997). They recovered more than $66 \%$ of their MRSA isolates from males. The higher prevalence of MRSA in males may be attributed to the fact that exposure in males working as farmers, veterinarians, workers and milkers is greater (Baddour et al., 2006). Concerning age of the examined patients, the difference in MRSA prevalence between the three age groups was statistically insignificant $(\mathrm{OR}=1.43,95 \% \mathrm{CI}=0.57-3.59, \mathrm{P}=0.45)$, which indicate that infection with MRSA is not related to the age of the patient.

Most of human patients subjected to our study were originally from rural village of Assiut (47 out of 63) and $17.0 \%$ of them were positive to MRSA infection. Statistically the higher prevalence of MRSA in patients from rural areas than those from urban areas were highly significant $(\mathrm{OR}=0.66,95 \% \mathrm{CI}=0.49-0.87, \mathrm{P}=0.003)$. In rural areas, individuals usually keep their animals in the house where there is a close daily contact between these individuals and their animals. Most of animal's MRSA infections are skin and soft tissue infections (Seguin et al., 1999). Close contact of human with animals gives the opportunity for horizontal transmission of MRSA between them (Morgan, 2008). Historically, MRSA infections in companion animals caused by strains resembling human strains (Rich and Roberts, 2004). Veterinary personnel may play a role as a source of MRSA infection to animals (Walther et al., 2009). MRSA infected animals like cattle may act as a reservoir for transmission of infection to other animals and their human handlers (AVMA, 2014; Klevens et al., 2007). Owners, farmers, veterinarians, milkers and people working at slaughter houses who meet MRSA colonized or infected animals are at risk to be colonized by MRSA (Paterson et al., 2012). MRSA transmission from horses to humans was also documented especially with animals 
experienced skin infections (Weese et al., 2006). 10 $(9.7 \%)$ of 103 tested veterinary hospital personnel in a large animal clinic were colonized with MRSA and pyogenic skin infections were recorded in 3 of them (Weese et al., 2006).

Antimicrobial testing and analysis for presence of antibiotic resistance genes were employed in this study. The analyzed genes were the most frequently associated with resistance of $S$. aureus (Beninati et al., 2015). All the identified MRSA strains were both phenotypically (MICs $8-128 \mu \mathrm{g} / \mathrm{mL}$ ) and genotypically (mecA-positive) resistant to penicillin and ampicillin. Lee (2003) also found that all MRSA isolates were resistant to penicillin and ampicillin. Moreover, Ahmed et al. (2014) found that all MRSA isolates recovered from infected surgical sites were completely resistant to $\beta$-lactams. A $100 \%$ of animal MRSA strains and more than $55 \%$ of man strains were shown to be resistant to the cephalosporin antibiotic (cefixime), meanwhile higher resistance rates reported by Vinodkumar et al. (2011) and lower rates were recorded by Sasikala et al. (2007). Previous studies, also done in Egypt, reported that $\beta$-lactams, macrolides and cephalosporins were the most prescribed antibiotics in Egyptian hospitals (Abdel-Maksoud et al., 2016). Tetracycline resistance was also common, especially among cattle and sheep MRSA isolates and in $44.4 \%$ of human isolates. Meanwhile, equine isolates and the remaining $55.6 \%$ of human isolates were sensitive to tetracycline despite that all MRSA strains were positive to tet $K$ and tet $M$ resistance genes. El-Jakee et al. (2011) also studied the antimicrobial resistance in MRSA isolates from cattle and human in Egypt and found high resistance rate to penicillin followed by oxytetracycline of these isolates. Rajala-Schultz et al. (2004), Wang et al. (2008), Coelho et al. (2009) and Bhatt et al. (2011) indicated that $\beta$-lactams (penicillins) and tetracycline are widely used for intra-mammary treatment of staphylococcal bovine mastitis, therefore these drugs most frequently associated with resistance.

Due to the close structural similarity of tetracycline resistance plasmids of different staphylococcal species from man and animals, the exchange of tetracycline resistance genes between man's and animal's staphylococci is possible (Schwarz et al., 1998). Tetracyclines are not commonly used in treatment of bacterial infections of horses in Egypt which explains the sensitivity of equine isolates to oxytetracycline but the present of the resistance genes of tetracycline may indicate the transmission of MRSA infection from another animal species or from human handlers (Pantosti, 2012). On the other hand, presence of tetracycline resistance genes in all human isolates even the phenotypically sensitive ones indicate the risk of transmission of these isolates from food animals where tetracycline is widely used (Lewis et al., 2008). Transfer of MRSA from food animals to human is possible, which may lead to convey of novel resistance genes (Pantosti, 2012).

Except for cow's isolates, the recovered MRSA strains in this study were sensitive to clindamycin. Clindamycin is frequently used in human patients to treat skin and soft tissue infections, because of its ability to distribute well into skin structures and to inhibit toxins production in staphylococci (Levin et al., 2005; Coyle et al., 2003; Stevens et al., 1988). However, the possibility of inducible resistance during therapy with clindamycin is a major concern, that inducible resistance does not usually appear in susceptibility testing and molecular detection of resistance genes (erm genes) is necessary (Abdel Fattah and Darwish, 2012). Expression of erm genes may be either constitutive or inducible and staphylococci with inducible resistance against clindamycin are sensitive to the drug if no inducer is present (Steward et al., 2005). This could explain the presence of $\operatorname{erm}(A)$ and $\operatorname{erm}(C)$ genes in phenotypically sensitive isolates to clindamycin.

All the 16 MRSA isolates recovered in this study were sensitive to vancomycin with MICs laying in the $0.5-4 \mu \mathrm{g} / \mathrm{ml}$ range. This could be explained by the fact that vancomycin use in human Egyptian out patients is not common due to lack of oral bioavailability and it is usually used in intensive care units for life-threatening conditions (Abdel Fattah and Darwish, 2012). Moreover, vancomycin is not used in veterinary Egyptian field.

MRSA isolates showed no resistance against ciprofloxacin and enerofloxacin. This finding agreed with Lee (2003) and Kumar et al. (2017), they found that MRSA isolates were susceptible to fluoroquinolones like ciprofloxacin and norfloxacin. Although the fluoroquinolones are not new antibiotics but its use in Egyptian field is not common like penicillines and cephalosporins. They don't affect by $\beta$-lactamase enzymes or altered by penicillin binding proteins so, it might be less likely to develop resistance (Kayser, 1985).

\section{Conclusion}

The study documented the isolation of MRSA from clinical specimens in several animal species at Assiut Governorate and the recovery of MRSA from human individuals at the same area. This suggests that transmission between animals and humans can be of both veterinary and public health importance. Zoonotic transmission risk may be real, it should be considered when handling animals with skin and soft tissue infections especially horses. Antibiotic susceptibility of bacteria isolated from suppurative skin lesions is recommended to guide individual therapy and to limit misuse of antimicrobials. Absence of concurrent sampling of animals and their in-contact humans and the limited number of MRSA cases in the study necessitates 
the further investigation on the epidemiology of MRSA infection in animals and humans in the study area.

\section{Acknowledgment}

We would like to thank Dr. Mohamed Seleem of Purdue University for providing the antibiotics and some of the equipment used in this study.

\section{Funding Information}

Authors received no funding.

\section{Author's Contributions}

Maha I. Hamed: Helped in collection of animal samples, shared in the practical part and wrote the manuscript.

Sylvia O. Ahmed: Shared in the practical part.

Doaa S. Sayed: Helped in collection of human samples.

Hossam-Elden M. Hassan: Collected human and animal samples, helped in the practical part.

\section{Conflict of Interest}

Authors declare that there is no conflict of interests.

\section{References}

Abd El-Hamid, M.I. and M.M. Bendary, 2015. Comparative phenotypic and genotypic discrimination of methicillin resistant and susceptible Staphylococcus aureus in Egypt. Cell. Mol. Biol., 61: 101-112. DOI: $10.14715 / \mathrm{cmb} / 2015.61 .4 .17$

Abdel Fattah, N.S.A. and Y.W. Darwish, 2012. Antibiogram testing of pediatric skin infections in the era of methicillin-resistant Staphylococci aureus: An Egyptian university hospital-based study. Int. J. Dermatol., 51: 1441-1447.

DOI: $10.1111 / \mathrm{j} .1365-4632.2012 .05515 . \mathrm{x}$

Abdel-Maksoud, M., M. El-Shokry, G. Ismail, S. Hafez and A. El-Kholy et al., 2016. Methicillin-resistant Staphylococcus aureus recovered from healthcareand community-associated infections in Egypt. Int. J. Bacteriol., 2016: 1-5. DOI: $10.1155 / 2016 / 5751785$

Ahmed, E.F., G.F.M. Gad, A.M. Abdalla, A.M. Hasaneen and S.F. Abdelwahab, 2014. Prevalence of methicillin resistant Staphylococcus aureus among Egyptian patients after surgical interventions. Surg. Infect. (Larchmt), 15: 404-411. DOI: $10.1089 /$ sur.2013.212

Ariza-Miguel, J., M. Hernández, I. Fernández-Natal and D. Rodríguez-Lázaro, 2014. Methicillin-resistant Staphylococcus aureus harboring mecC in livestock in Spain. J. Clin. Microbiol., 52: 4067-4069.

DOI: $10.1128 / J C M .01815-14$
AVMA, 2014. American Veterinary Medical Association. https://www.avma.org/KB/Resources/FAQs/Pages/ MRS

Baddour, M.M., M.M. Abuelkheir and A.J. Fatani, 2006. Trends in antibiotic susceptibility patterns and epidemiology of MRSA isolates from several hospitals in Riyadh, Saudi Arabia. Ann. Clin. Microbiol. Antimicrob., 5: 1-11. DOI: $10.1186 / 1476-0711-5-30$

Baptiste, K.E., K. Williams, N.J. Willams, A. Wattret and P.D. Clegg et al., 2005. Lewis_Interventions, 11: 2004-2006.

Beninati, C., F. Reich, D. Muscolino, F. Giarratana and A. Panebianco et al., 2015. ESBL-producing bacteria and MRSA isolated from poultry and turkey products imported from Italy. Czech J. Food Sci., 33: 97-102. DOI: $10.17221 / 428 / 2014-C J F S$

Bhanderi, B.B. and M.K. Jhala, 2011. Review article ANIMALS. Drugs, 2: 153-160.

Bhatt, V.D., M.S. Patel, C.G. Joshi and A. Kunjadia, 2011. Identification and antibiogram of microbes associated with bovine mastitis. Anim. Biotechnol., 22: 163-169. DOI: 10.1080/10495398.2011.570132

Borg, M.A., M. De Kraker, E. Scicluna, N. van de Sande-Bruinsma and E. Tiemersma et al., 2007. Prevalence of methicillin-resistant Staphylococcus aureus (MRSA) in invasive isolates from southern and eastern Mediterranean countries. J. Antimicrob. Chemother., 60: 1310-1315.

DOI: $10.1093 / \mathrm{jac} / \mathrm{dkm} 365$

Carter, G.R., M.M. Chengappa and A.W. Roberts, 1995. Essentials of Veterinary Microbiology. 5th Edn., Willians and Wilkins Baltimore.

Caruso, M., L. Latorre, G. Santagada, R. Fraccalvieri and A. Miccolupo et al., 2015. Methicillin-Resistant Staphylococcus aureus (MRSA) in sheep and goat bulk tank milk from Southern Italy. Small Rumin. Res., 135: 26-31.

DOI: $10.1016 /$ j.smallrumres.2015.12.023

CLSI, 2010. Clinical and Laboratory Standards Institute.

Coelho, S.M.O., E. Reinoso, I.A. Pereira, L.C. Soares and M. Demo et al., 2009. Virulence factors and antimicrobial resistance of Staphylococcus aureus isolated from bovine mastitis in Rio de Janeiro. Pesqui. Vet. Bras., 29: 369-374.

DOI: $10.1590 / \mathrm{S} 0100-736$ X2009000500002

Collins, C.H., P.M. Lyne and J.M. Grange, 1991. Collins and Lyne's Microbiological Methods. 6th Edn., Balterworth-Heinemann, Oxford, London.

Cortimiglia, C., V. Bianchini, A. Franco, A. Caprioli and A. Battisti et al., 2015. Short communication: Prevalence of Staphylococcus aureus and methicillin-resistant $S$. aureus in bulk tank milk from dairy goat farms in Northern Italy J. Dairy Sci., 98: 2307-2311. DOI: $10.3168 /$ jds.2014-8923 
Coyle, E.A., R. Cha and M.J. Rybak, 2003. Influences of linezolid, penicillin and clindamycin, alone and in combination, on streptococcal pyrogenic exotoxin A release. Antimicrob. Agents Chemother., 47: 17521755. DOI: $10.1128 /$ AAC.47.5.1752-1755.2003

Cruickshank, R., J.P. Duguid, B.R. Marmion and R.H.A. Swain, 1975. Medical Microbiology. 12th Edn., Living stone, London, New York.

Deurenberg, R.H. and E.E. Stobberingh, 2008. The evolution of Staphylococcus aureus. Infect. Genet. Evol., 8: 747-763.

DOI: 10.1016/j.meegid.2008.07.007

Devriese, L.A. and J. Hommez, 1975. Epidemiology of methicillin-resistant Staphylococcus aureus in dairy herds. Res. Vet. Sci., 19: 23-27.

Duijkeren, E.V., A.T.A. Box, M.E.O.C. Heck, W.J.B. Wannet and A.C. Fluit, 2004. Methicillin-resistant staphylococci isolated from animals. Vet Microbiol., 103: 91-97. DOI: 10.1016/j.vetmic.2004.07.014

El-Jakee, J.K., N.S. Atta, A.A. Samy, M.A. Bakry and E.A. Elgabry et al., 2011. Antimicrobial resistance in clinical isolates of Staphylococcus aureus from bovine and human sources in Egypt. Glob. Vet., 7: 581-586. DOI: 10.1016/j.medmal.2005.02.014

Falagas, M.E., D.E. Karageorgopoulos, J. Leptidis and I.P. Korbila, 2013. MRSA in Africa: Filling the global map of antimicrobial resistance. PLoS One. DOI: 10.1371 /journal.pone.0068024

Fessler, A.T., R.G.M. Olde Riekerink, A. Rothkamp, K. Kadlec and O.C. Sampimon et al., 2012. Characterization of methicillin-resistant Staphylococcus aureus CC398 obtained from humans and animals on dairy farms. Vet. Microbiol., 160: 77-84. DOI: 10.1016/j.vetmic.2012.05.005

Giacinti, G., V. Carfora, A. Caprioli, D. Sagrafoli and N. Marri et al., 2017. Prevalence and characterization of methicillin-resistant Staphylococcus aureus carrying mecA or mecC and methicillin-susceptible Staphylococcus aureus in dairy sheep farms in central Italy. J. Dairy Sci., 100: 7857-7863.

DOI: $10.3168 /$ jds.2017-12940

Guirguis, M.A., 2004. Antibiotic susceptibility pattern of gram-positive cocci isolates from different clinical samples in Sharkia Governorate with DNA study of the most resistant strains. Faculty of Medicine, Zagazig University.

Hadjirin, N.F., E.M. Lay, G.K. Paterson, E.M. Harrison and S.J. Peacock et al., 2015. Detection of livestockassociated meticillin-resistant staphylococcus aureus CC398 in retail pork, United Kingdom, february 2015. Eurosurveillance, 20: 1-4.

Hanselman, B.A., S.A. Kruth, J. Rousseau, D.E. Low and B.M. Willey et al., 2006. Methicillin resistant Staphylococcus aureus colonization in veterinary personnel. Emerg Infect. Dis., 12: 6-6.

DOI: $10.3201 /$ eid1212.060231
Hata, E., K. Katsuda, H. Kobayashi, I. Uchida and K. Tanaka et al., 2010. Genetic Variation among Staphylococcus aureus Strains from Bovine Milk and Their Relevance to Methicillin-Resistant Isolates from Humans. J. Clin. Microbiol., 48: 2130-2139. DOI: $10.1128 / \mathrm{jcm} .01940-09$

Herold, B.C., L.C. Immergluck, M.C. Maranan, D.S. Lauderdale and R.E. Gaskin et al., 1998. Community-acquired methicillin-resistant Staphylococcus aureus in children with no identified predisposing risk. JAMA, 279: 593-598.

Jayaweera, J.A.A.S. and W.W. Kumbukgolla, 2017. Antibiotic resistance patterns of MethicillinResistant Staphylococcus aureus (MRSA) isolated from livestock and associated farmers in Anuradhapura, Sri Lanka. Germs, 7: 132-139. DOI: $10.18683 /$ germs.2017.1118

Juhász-Kaszanyitzky, É., S. Jánosi, P. Somogyi, Á. Dán and L. Van Der Graaf-van Bloois et al., 2007. MRSA transmission between cows and humans. Emerg. Infect. Dis. 13: 630-632. DOI: 10.3201/eid1304.060833

Kayser, F.H., 1985. The quinolones: mode of action and mechanism of resistance. Res. Clin. Forums, 7: 17-27.

Klevens, R.M., M.A. Morrison, J. Nadle, S. Petit and K. Gershman et al., 2007. Invasive methicillin-resistant Staphylococcus aureus infections in the United States. JAMA, 298: 1763-1771. DOI: $10.1001 /$ jama.298.15.1763

Kumar, A., P. Kaushik, Anjay, P. Kumar and M. Kumar, 2017. Prevalence of methicillin-resistant Staphylococcus aureus skin and nasal carriage isolates from bovines and its antibiogram. Vet. World, 10: 593-597.

DOI: 10.14202/vetworld.2017.593-597

Lee, J.H., 2003. Methicillin (Oxacillin)-Resistant Staphylococcus aureus Strains Isolated from major food animals and their potential transmission to humans. Applied Environ. Microbiol., 69: 6489-6494. DOI: 10.1128/AEM.69.11.6489

Leonard, F.C. and B.K. Markey, 2008. Meticillinresistant Staphylococcus aureus in animals: A review. Vet. J., 175: 27-36.

DOI: $10.1016 / j . t v j 1.2006 .11 .008$

Leonard, F.C., Y. Abbott, A. Rossney, P.J. Quinn and R. O'Mahony et al., 2006. Methicillin-resistant Staphylococcus aureus isolated from a veterinary surgeon and five dogs in one practice. Vet. Rec., 158: 155-159. DOI: 10.1136/vr.158.5.155

Levin, T.P., B. Suh, P. Axelrod, A.L. Truant and T. Feketem, 2005. Potential clindamycin resistance in clindamycin-susceptible, erythromycin-resistant Staphylococcus aureus: Report of a clinical failure. Antimicrob. Agents Chemother., 49: 1222-1224. DOI: 10.1128/AAC.49.3.1222-1224.2005 
Lewis, H.C., K. Mølbak, C. Reese, F.M. Aarestrup and M. Selchau et al., 2008. Pigs as source of methicillin-resistant Staphylococcus aureus CC398 infections in humans, Denmark. Emerg. Infect. Dis., 14: 1383-1389. DOI: 10.32007-1576Research

Louie, J., J. Goodfellow, P. Mathieu, A. Glatt and M. Louie et al., 2009. Rapid detection of methicillinresistant staphylococci from blood culture bottles by using a multiplex PCR assay. J. Clin. Microbiol., 40: 2786-2790. DOI: 10.1128/JCM.40.8.2786

Moran, G.J., A. Krishnadasan, R.J. Gorwitz, G.E. Fosheim and L.K. McDougal et al., 2006. Methicillin-resistant $S$. aureus infections among patients in the emergency department. N. Engl. J. Med., 355: 666-674. DOI: 10.1056/NEJMoa055356

Morgan, M., 2008. Methicillin-resistant Staphylococcus aureus and animals: Zoonosis or humanosis? J. Antimicrob. Chemother., 62: 1181-1187. DOI: $10.1093 / \mathrm{jac} / \mathrm{dkn} 405$

O'Mahony, R., Y. Abbott, F.C. Leonard, B.K. Markey and P.J. Quinn et al., 2005. Methicillin-resistant Staphylococcus aureus (MRSA) isolated from animals and veterinary personnel in Ireland. Vet. Microbiol., 109: 285-296. DOI: $10.1016 /$ j.vetmic. 2005.06 .003

Pantosti, A., 2012. Methicillin-resistant Staphylococcus aureus associated with animals and its relevance to human health. Front. Microbiol., 3: 1-12. DOI: $10.3389 /$ fmicb.2012.00127

Paterson, G.K., J. Larsen, E.M. Harrison, A.R. Larsen and F.J. Morgan et al., 2012. First detection of livestock-associated meticillin-resistant Staphylococcus aureus CC398 in bulk tank milk in the United Kingdom, January to July 2012. Euro Surveill., 17: 20337-20337.

Pexara, A., N. Solomakos, D. Sergelidis, A.S. Angelidis and A. Govaris, 2005. Occurrence and antibiotic resistance of enterotoxigenic Staphylococcus aureus in raw ovine and caprine milk in Greece. Dairy Sci. Technol.

Quinn, P., B. Markey and J. Carter, 1994. Clin. Vet. Microbiol.

Rajala-Schultz, P.J., K.L. Smith, J.S. Hogan and B.C. Love, 2004. Antimicrobial susceptibility of mastitis pathogens from first lactation and older cows. Vet. Microbiol., 102: 33-42.

DOI: $10.1016 /$ j.vetmic. 2004.04 .010

Rich, M. and L. Roberts, 2004. Methicillin-resistant Staphylococcus aureus isolates from companion animals. Vet. Rec., 154: 310-310.

Sabry, N.A., S.F. Farid and D.M. Dawoud, 2014. Antibiotic dispensing in Egyptian community pharmacies: An observational study. Res. Soc. Adm. Pharm., 10: 168-184.
Sasikala, R., R. Latha, N. Muruganandam and K. Senthilkumar, 2007. Surveillance on Multi Drug Resistant Organism (MDRO) associated with Diabetic Foot Ulcers in Pondicherry. Internet J. Microbiol., 5: 1-7.

Schwarz, S., M.C. Roberts, C. Werckenthin, Y. Pang and C. Lange, 1998. Tetracycline resistance in Staphylococcus spp. from domestic animals. Vet. Microbiol., 63: 217-227. DOI: 10.1016/S0378-1135(98)00234-X

Seguin, J.C., R.D. Walker, J.P. Caron, W.E. Kloos and C.G. George et al., 1999. Methicillin-resistant Staphylococcus aureus outbreak in a veterinary teaching hospital: Potential human-to-animal transmission. J. Clin. Microbiol., 37: 1459-1463.

Sobhy, N., F. Aly, O.A. El Kader, A. Ghazal and A. Elbaradei, 2012. Community-acquired methicillinresistant Staphylococcus aureus from skin and soft tissue infections (in a sample of Egyptian population): Analysis of MEC gene and staphylococcal cassette chromosome. Brazilian J. Infect. Dis., 16: 426-431. DOI: $10.1016 /$ j.bjid.2012.08.004

Stevens, D.L., A.E. Gibbons, R. Bergstrom and V. Winn, 1988. The Eagle effect revisited: Efficacy of clindamycin, erythromycin and penicillin in the treatment of streptococcal myositis. J. Infect. Dis., 158: $23-28$.

Steward, C.D., P.M. Raney, A.K. Morrell, P.P. Williams and L.K. McDougal et al., 2005. Testing for induction of clindamycin resistance in erythromycin-resistant isolates of Staphylococcus aureus. J. Clin. Microbiol., 43: 1716-1721.

DOI: $10.1128 /$ JCM.43.4.1716-1721.2005

Strommenger, B., C. Kettlitz, G. Werner and W. Witte, 2003. Multiplex PCR assay for simultaneous detection of nine clinically relevant antibiotic resistance genes in Staphylococcus aureus. J. Clin. Microbiol., 41: 4089-4094.

DOI: $10.1128 /$ JCM.41.9.4089

Tentolouris, N., G. Petrikkos, N. Vallianou, C. Zachos and G.L. Daikos et al., 2006. Prevalence of methicillin-resistant Staphylococcus aureus in infected and uninfected diabetic foot ulcers. Clin. Microbiol. Infect., 12: 186-189.

DOI: 10.1111/j.1469-0691.2005.01279.x

Van Belkum, A., M. Vandenbergh, G. Kessie, S.M. Qadri and G. Lee et al., 1997. Genetic homogeneity among methicillin-resistant Staphylococcus aureus strains from Saudi Arabia.. Microb. Drug Resist., 3: 365-369.

DOI: $10.1089 / \mathrm{mdr} .1997 .3 .365$ 
Van Cleef, B.A.G.L., E.M. Broens, A. Voss, X.W. Huijsdens and L. Züchner et al., 2010. High prevalence of nasal MRSA carriage in slaughterhouse workers in contact with live pigs in The Netherlands. Epidemiol. Infect., 138: 756-763. DOI: $10.1017 / \mathrm{S} 0950268810000245$

Vanderhaeghen, W., K. Hermans, F. Haesebrouck and P. Butaye, 2010. Methicillin-Resistant Staphylococcus aureus (MRSA) in food production animals. Epidemiol. Infect., 138: 606-625.

DOI: $10.1017 / \mathrm{S} 0950268809991567$

Vinodkumar, C.S., H. Srinivasa, K.G. Basavarajappa, S. Geethalakshmi and N. Bandekar, 2011. Isolation of bacteriophages to multi-drug resistant Enterococci obtained from diabetic foot: A novel antimicrobial agent waiting in the shelf? Indian J. Pathol. Microbiol., 54: 90-95.

DOI: $10.4103 / 0377-4929.77333$

Walther, B., L.H. Wieler, A.W. Friedrich, B. Kohn and L. Brunnberg et al., 2009. Staphylococcus aureus and MRSA colonization rates among personnel and dogs in a small animal hospital: Association with nosocomial infections. Berl. Munch. Tierarztl. Wochenschr., 122: 178-185.
Wang, Y., C.M. Wu, L.M. Lu, G.W.N. Ren and X.Y. Cao et al., 2008. Macrolide-lincosamide-resistant phenotypes and genotypes of Staphylococcus aureus isolated from bovine clinical mastitis. Vet. Microbiol., 130: 118-125.

DOI: $10.1016 /$ j.vetmic.2007.12.012

Weese, J.S., 2010. Methicillin-resistant Staphylococcus aureus in animals. ILARJ, 51: 233-244. DOI: 10.1016/B978-0-12-374984-0.01473-X

Weese, J.S., F. Caldwell, B.M. Willey, B.N. Kreiswirth and A. McGeer et al., 2006. An outbreak of methicillinresistant Staphylococcus aureus skin infections resulting from horse to human transmission in a veterinary hospital. Vet. Microbiol., 114: 160-164. DOI: 10.1016/j.vetmic.2005.11.054

Weese, J.S., J. Rousseau, J.L. Traub-Dargatz, B.M. Willey and A.J. McGeer et al., 2005. Communityassociated methicillin-resistant Staphylococcus aureus in horses and humans who work with horses. J. Am. Vet. Med. Assoc., 226: 580-583.

Weese, J.S., T. DaCosta, L. Button, K. Goth and M. Ethier et al., 2004. Isolation of methicillin-resistant Staphylococcus aureus from the environment in a Veterinary Teaching Hospital. J. Vet. Intern. Med., 18: 468-470. DOI: 10.1892/08916640(2004)18<468:IOMSAF>2.0.CO;2 